\title{
DIAGNÓSTICO SOBRE OS ACIDENTES DE TRÂNSITO COM MOTOCICLETAS NA CIDADE DE UBERLÂNDIA (MG) NO ANO DE 2002: UMA INTER- RELAÇÃO COM A SUSTENTABILIDADE URBANA
}

Diagnosis of the Traffic Accidents with motorcycles in the city of Uberlândia (MG) in the year of 2002: An inter-relationship with Sustainable Urban

El diagnóstico de los accidentes de tráfico con motocicletas en la ciudad de Uberlândia (MG) nel año 2002: Una interrelación con la sostenibilidad urbana

Anaísa Filmiano Andrade Lopes Mestranda em Arquitetura e Urbanismo, UFU, Brasil ana_isaandrade@hotmail.com

Lorrayne da Silva Brito Mestranda em Arquitetura e Urbanismo, UFU, Brasil lorrayne_brito@hotmail.com 


\section{RESUMO}

Atualmente, percebe-se que os índices de acidentes de trânsito são alarmantes, principalmente nos países em desenvolvimento. No Brasil, estes índices permanecem elevados e o número absoluto de vítimas vem crescendo. Diante disto, o presente estudo tem como objetivo analisar os acidentes de trânsito envolvendo motocicletas na cidade de Uberlândia - MG, tendo como recorte temporal o ano de 2002. Para tanto, o procedimento metodológico pautou-se em pesquisa bibliográfica e empírica, realizando-se aprofundamentos sobre a temática em livros, artigos, dissertações, legislações, teses e outros; e pesquisas de campo na cidade em estudo, especificamente na Secretaria de Gerenciamento e Controle de Tráfego - VERTRAN, Secretaria de Trânsito e Transportes - SETTRAN, no Corpo de Bombeiros Militar de Minas Gerais - CBMMG, na Polícia Militar - PML e no Hospital de Clínicas de Uberlândia - HCU (setor de estatística). Os resultados apontam que com relação à severidade, $77,93 \%$ dos acidentados sofreram danos materiais, $17,98 \%$ sofreram ferimentos leves, 3,82\% ferimentos graves e $0,28 \%$ de mortes. A faixa etária de maior envolvimento nos acidentes foi a de jovens de 20 a 29 anos e a maior frequência dos mesmos ocorrem no final da semana e durante a semana, se mantendo homogêneos. Pode-se concluir que ao definir a gravidade do problema podem-se elaborar políticas públicas e agir a curto e médio prazo como forma de combater acidentes, gerar segurança, promover a saúde pública, melhorar a qualidade de vida da população e caminhar rumo à sustentabilidade urbana.

PALAVRAS-CHAVE: Acidentes de Trânsito. Motociclistas. Sustentabildiade Urbana. Uberlândia/MG.

\section{ABSTRACT}

Currently, it is noticed that the traffic accident rates are alarming, especially in developing countries. In Brazil, these rates remain high and the absolute number of victims is growing. In view of this, the present study aims to analyze traffic accidents involving motorcycles in the city of Uberlândia - MG, with the time frame 2002. Therefore, the methodological procedure was marked on literature and empirical research, is performing insights on the theme in books, articles, dissertations, legislation, theses and others; and field research in the city under study, specifically in the Department of Management and Traffic Control - VERTRAN, Department of Traffic and Transportation SETTRAN, the Fire Brigade of Minas Gerais - CBMMG, the Military Police - PML and Clinical Hospital Uberlandia $\mathrm{HCU}$ (statistical sector). The results show that with respect to severity, $77.93 \%$ of the victims suffered damage, $17.98 \%$ suffered minor injuries, $3.82 \%$ and $0.28 \%$ severe injury deaths. The age group most involved in accidents was the young 20 to 29 years and the highest frequency of these occur during the week and during the week, remaining homogeneous. It can be concluded that to define the severity of the problem can be elaborate public policies and act in the short and medium term as a way to combat accidents, generate security, promote public health, improve the quality of life of the population and move towards sustainability urban.

KEYWORDS: Traffic-accidents. Motorcyclists. Sustainable Urban. Uberlândia / MG.

\section{RESUMEN}

En la actualidad, se observa que las tasas de accidentes de tráfico son alarmantes, especialmente en los países en desarrollo. Nel Brasil, estas tasas siguen siendo elevadas y el número absoluto de víctimas ven aumento. En vista de esto, el presente estudio tiene como objetivo analizar los accidentes de tránsito que involucran motocicletas en la ciudad de Uberlândia - MG, con el marco de tiempo de 2002. Por lo tanto, el procedimiento metodológico fue uma investigación de literatura y empírica, realizando estudios sobre el tema en libros, artículos, tesis, legislación y otros; y la investigación de campo en la ciudad en estudio, específicamente en el Departamento de Gestión y Control de Tráfico - VERTRAN, Departamento de Tránsito y Transporte - SETTRAN, el Cuerpo de Bomberos de Minas Gerais CBMMG, la Policía Militar - LMP y Hospital del Clínica in Uberlandia - HCU (sector de la estadística). Los resultados muestran que con respecto a la gravedad, $77,93 \%$ de las víctimas sufrió daños, $17,98 \%$ sufrió lesiones menores, $3,82 \%$ y $0,28 \%$ graves muertes por lesiones. El grupo de edad más involucrados en accidentes fueron los jóvenes de 20 a 29 años y la mayor frecuencia de éstos se producen durante la semana y durante los fines de semana, permaneciendo homogéneo. Se puede concluir que al definir la gravedad del problema puede elaborar las políticas públicas y actuar a corto y medio plazo como una manera de combatir los accidentes, generar seguridad, promover la salud pública, mejorar la calidad de vida de la población y avanzar hacia la sostenibilidad urbana.

PALABRAS-CLAVE: Los accidentes de tráfico. Motociclistas. Urbano sostenible. Uberlândia/MG. 


\section{INTRODUÇÃO}

Atualmente os acidentes de trânsito (AT) constituem um problema urbano, principalmente referente à saúde pública em virtude de serem acompanhados por elevado índice de morbimortalidade e encontram-se entre as causas externas de maior incidência, com elevado percentual de internação, além de altos custos hospitalares, perdas materiais, despesas previdenciárias e sofrimento para as vítimas e seus familiares. A Organização Mundial de Saúde estima que em 2020 os acidentes de trânsito sejam a segunda causa de morte prematura no mundo (DAVANTEL et al., 2009). No Brasil, eles configuram um problema social e econômico de grande impacto representando mais de um quarto das mortes violentas (WHO, 2004).

Portanto, este indicador esta inter-relacionado com a sustentabilidade urbana, uma vez que estudá-lo é fundamental para promover a mobilidade sustentável e reconhecer a interdependência entre a saúde, o ambiente e o direito à cidade. O Programa Cidades Sustentáveis, determina que a meta de sustentabilidade referente às mortes com motocicleta deve ser equivalente a zero, ou seja, devem-se zerar as mortes dos usuários deste meio automotor. No entanto, observa-se o aumento do número de motocicletas nas vias urbanas e, consequentemente, na vulnerabilidade e exposição ao risco de acidentes dos usuários.

Sabe-se que embora as motocicletas representem menor frota em relação aos automóveis (25\%) elas contribuem com o maior número de vítimas (56\%) e, por isso, captam $47 \%$ do valor das indenizações pagas pelo Seguro de Danos Pessoais Causados por Veículos Automotores de Vias Terrestres - DPVAT (BRASIL, 2005). Em Uberlândia, cidade de estudo desta pesquisa, o número de óbitos e a morbidade por AT vêm crescendo desde a década de 70, não atingindo assim, a meta de sustentabilidade determinada pelo Programa Cidades Sustentáveis. Um estudo, no período de 1960 e 1980, feito por Goulart e Ribeiro (1985), mostra como evoluíram ao longo de 20 anos, os óbitos nessa cidade e chamam a atenção para o grupo de acidentes, violências e traumatismos.

Atualmente, uma das ferramentas que se têm mostrado útil para entender o sistema urbano é a utilização de indicadores. Indicadores estes compostos por aspectos de saúde, educação, meio ambiente, mobilidade urbana, planejamento e desenho urbano, dentre outros. Diante disto, a escolha da temática se justifica, pois o indicador acidentes de trânsito é um dos indicadores que também deve ser analisado para que as cidades caminhem rumo ao desenvolvimento sustentável. Portanto, tornam-se necessários estudos detalhados, que sejam capazes de apontar como, quando e por quais razões ocorrem, quem é vulnerável, em que grau e por quais motivos. Esse conhecimento é capaz de representar o elemento fundamental para o estabelecimento seguro de medidas visando a sua prevenção, além da formulação de políticas, a fim de garantir a população melhores condições em seus deslocamentos, eficiência e segurança. Diante desse contexto, esta pesquisa tem como objetivo analisar os acidentes de 


\section{ANAP \\ Brasil \\ ISSN 1984-3240 \\ v. 9, n. 14}

trânsito envolvendo motocicletas na cidade de Uberlândia - MG, tendo como recorte temporal o ano de 2002.

\section{METODOLOGIA}

O estudo científico deve apresentar um recorte espacial e temporal para facilitar o entendimento do procedimento metodológico adotado. Portanto, nesta pesquisa o recorte espacial, refere-se a cidade de Uberlândia, Minas Gerais. Já o recorte temporal, refere-se ao ano de 2002, ressalta-se que este período foi escolhido, devido à disponibilidade de dados e informações que foram fornecidas pela Secretaria de Gerenciamento e Controle de Tráfego VERTRAN da cidade de Uberlândia.

A pesquisa se caracteriza como quali-quantitativa, uma vez que busca descobrir fatos ou situações investigando alternativas de análise, neste caso, por meio dos dados e informações referentes aos acidentes envolvendo motociclistas. A mesma também pode ser caracterizada como empírica, uma vez em que foram realizadas pesquisas de campo na cidade em estudo e também como bibliográfica, onde foram realizados levantamentos e aprofundamentos sobre a temática em livros, artigos, dissertações, legislações, teses e outros.

Inicialmente, o procedimento metodológico embasou-se na pesquisa bibliográfica, a partir de leituras de estudos nacionais e internacionais que abordam sobre a temática acidentes de trânsito. Para selecionar o grupo de pessoas a serem estudadas, utilizou-se a definição de motociclista de acordo com a Classificação Internacional de Doenças da Organização Mundial da Saúde (OMS, 2000, p. 47): "é toda pessoa que viaja sobre uma motocicleta ou side-car ou um reboque fixado a esse veículo". Foram utilizadas, também, as seguintes definições: Acidente de Trânsito "é todo acidente com veículo ocorrido na via pública (OMS, 2000, p. 48).

Posteriormente, para aprofundamento dos acidentes de trânsito envolvendo motociclistas em Uberlândia, foram realizados trabalhos de campo in loco para coleta de dados na Secretaria de Gerenciamento e Controle de Tráfego - VERTRAN, Secretaria de Trânsito e Transportes SETTRAN, no Corpo de Bombeiros Militar de Minas Gerais - CBMMG, na Polícia Militar - PML e no Hospital de Clínicas de Uberlândia - HCU (setor de estatística). Portanto, este estudo partiu da pesquisa bibliográfica e empírica, proporcionando as seguintes análises:

1. Acidentes de trânsito envolvendo motociclistas em Uberlândia-MG - 2002

2. Ocorrências de AT com motociclistas e total de acidentes por tipo de severidade

3. Gênero e faixa etária dos condutores envolvidos em AT

4. Horário, dia da semana e mês de maior ocorrência de acidentes

5. Internações hospitalares de motociclistas vítimas de AT e o número absoluto de vítimas fatais

\section{REFERENCIAL TEÓRICO}




\subsection{Aspectos Gerais sobre os Condutores de Motocicleta e os Acidentes de Trânsito}

A motocicleta diz respeito a todo veículo que possui duas rodas. Há diferenças dos modelos, como peso, tamanho do motor, velocidade máxima limite, estabilidade e potência. Portanto, há diferenças também no que se refere à segurança (ZAMBON \& HASSELBERG, 2006). E devido à demanda da população por um transporte ágil e rápido surge a profissão do moto-taxista, que, além disso, conta com o baixo custo médio de combustível e a relativa facilidade na aquisição da motocicleta (RIBEIRO, 2006). Tem crescido também o número de empresas especializadas na prestação de serviços de entrega, tais como copiadoras, distribuidora de gás de cozinha, farmácias, entre outras. De acordo com Diniz et al. (2005), as formas de remuneração podem ser por produtividade ou por valor fixo mensal, sendo que a remuneração mais comum, por produtividade, pode ser determinada através do pagamento por hora, por deslocamento, ou comissão por entrega. Estes aspectos podem agravar ainda mais os AT, pois faz com que os motociclistas excedam o limite de velocidade.

Em relação aos aspectos legais, as normas gerais de circulação e conduta dos usuários das vias terrestres são estabelecidas no Capítulo III do Código de Trânsito Brasileiro (CTB), Lei № 9.503, de 1997 (BRASIL, 2005). No que se refere à regulamentação da atividade de condutor remunerado de transporte de carga por motocicleta como profissão, pode-se afirmar que esta continua ainda sem uma lei que a regularize (FERREIRA, 2009). Existem apenas Projetos de Lei que visam regulamentar esta atividade, um deles é o projeto de Lei № 10115 de 2003.

Em relação aos custos sociais e econômicos dos AT, segundo o Instituto de Pesquisa Econômica Aplicada - IPEA (2008) pode-se destacar que no Brasil, 2\% do PIB são usados anualmente em conseqüência dos acidentes de trânsito. As mortes ocupam a terceira posição no quadro geral de óbitos, ficando atrás apenas das causadas por doenças cardíacas e degenerativas (MÂNICA, 2007). Esses dados evidenciam o quanto os acidentes de trânsito representam um problema urbano, principalmente para a saúde pública, além disso, se enquadram na classificação de "problema prevenível", mais o que se nota não são prevenções e reduções, mas sim um gasto cada vez maior com as vítimas e o aumento de vidas perdidas. Desse modo, os acidentes de trânsito, inclusive os que envolvem motocicletas, provocam uma insustentabilidade urbana, pois além das perdas econômicas, têm-se as perdas sociais, a interrupção prematura de vidas, a incapacidade física e emocional dos vitimados sobreviventes, perda por produção, dentre outros. De acordo com Rogers (2008), para caminhar rumo a sustentabilidade urbana é necessário planejar a cidade, promover a acessibilidade e intensificar o uso de sistemas mais eficiente de transportes.

\section{RESULTADOS E DISCUSSÃO}




\section{ANAP Brasil \\ ISSN 1984-3240 \\ v. 9, n. 14}

\section{REVISTA CIENTÍFICA 2016}

\subsection{Caracterização da Área de Estudo}

O município de Uberlândia localiza na mesorregião Triângulo Mineiro/Alto Paranaíba, no estado de Minas Gerais. Localiza-se a oeste da capital do estado, Belo Horizonte, distando desta cerca de 556 quilômetros, possui uma área total de $4.115,09 \mathrm{Km}^{2}$ e sua população, é de 619.536 habitantes (IBGE, 2012).

Mapa 1 - Localização do Município de Uberlândia-MG na mesorregião geográfica Triângulo Mineiro/Alto Paranaíba, 2010.

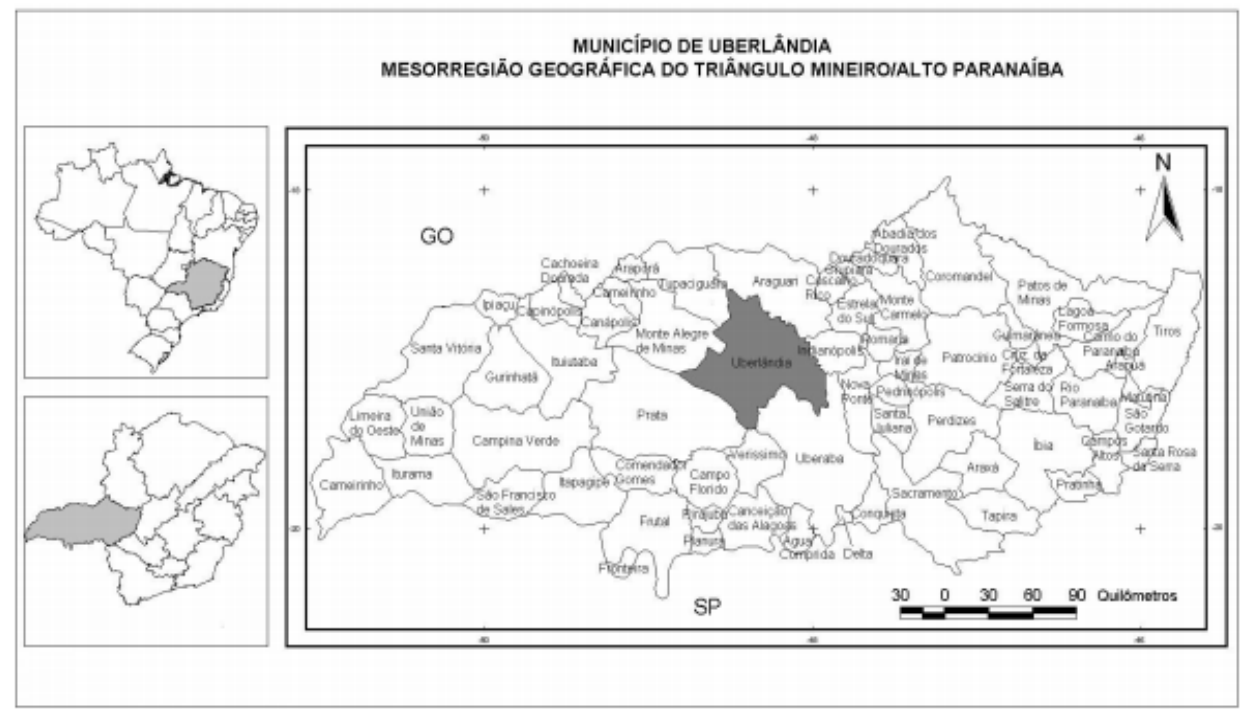

Fonte: IBGE, 2012. Org: VIEIRA, A S. 2012

Esse importante centro regional atrai a população de seu entorno, principalmente devido às atividades do setor terciário, gerando um crescimento populacional. Paralelamente a este crescimento observou-se o aumento progressivo da frota local de veículos que, segundo dados do DENATRAN (2003), aumentou de 170.500 em 2002, para 178.626 veículos em 2003 representando um crescimento em média de $4,5 \%$ ao ano. Este fato pode ser explicado pela soma de diversos fatores, como: a facilidade de acesso à compra deste veículo, inclusive pelas camadas de baixa renda, que pode ser adquirido por consórcios, títulos de capitalização e financiamentos em longo prazo; o aumento no valor dos combustíveis e a economia dos mesmos pelas motocicletas; a facilidade de deslocamento diante de congestionamentos; a fuga do problema causado pela saturação dos espaços destinados a estacionamento de veículos maiores, o surgimento principalmente após 1990 dos "motoboys", entre outros.

Nesse contexto, Uberlândia, assim como qualquer cidade brasileira, enfrenta problemas relacionados a questões de planejamento urbano. Dentre esses problemas, encontram-se os AT, inseridos num contexto mais amplo do planejamento da circulação. 


\subsection{Análise dos acidentes de trânsito envolvendo motociclistas em Uberlândia-MG - 2002}

Atualmente, em Uberlândia, as motocicletas apresentam uma significativa representação na frota de veículos e, infelizmente, representam uma parcela significante entre os veículos envolvidos em acidentes de trânsito. Ressalta-se que a atividade de moto-taxi não é regulamentada no município de Uberlândia, a despeito de varias cidades brasileiras, que regulamentaram o serviço, mesmo sem haver lei federal que respalde essa decisão, usando o direito do município em legislar sobre o planejamento de trânsito e transportes. Os mototaxistas de Uberlândia organizam-se, praticamente, de duas formas, trabalham vinculados às "centrais" ou individualmente. A carga horária trabalhada por dia revelou-se intensa, onde $11 \%$ dos mototaxistas trabalham mais de 16 horas por dia, o que pode elevar o número dos riscos de acidentes de trânsito (SILVA, 2006).

Em Uberlândia, no ano de 2002, registrou-se 7499 acidentes de trânsito, sendo que a Polícia Militar - PM registrou 2987 Boletins de Ocorrência - BO's, enquanto o Department of Transport - DOT registrou 4512 acidentes (Tabela 1).

Tabela 1: Quantidade de Boletins de Ocorrência registrados no ano de 2002, em Uberlândia.

\begin{tabular}{c|c|c|c}
\hline Ano & BO da PM & BO da DOT & Total de BO's registrados \\
\hline 2002 & 2987 & 4512 & 7499 \\
\hline
\end{tabular}

Fonte: SIGAT - Sistema de Informações Gerenciais de Acidentes de Trânsito/SETTRAN.Org.: LOPES , A. F. A., 2012.

As informações sobre a quantidade de acidentes relativa ao banco de dados de AT foram reunidas a partir dos BOs feitos pela Polícia Militar e operadores de Tráfego da Secretaria de Trânsito e Transportes - SETTRAN. No BO, é registrado o estado da vítima na cena do acidente, em sua maioria, sem o acompanhamento do estado das vítimas após o atendimento médicohospitalar.

\subsection{Ocorrências de AT com motociclistas e total de acidentes por tipo de severidade}

As informações sobre os AT motociclísticos foram buscadas também por meio das ocorrências de atendimento do Corpo de Bombeiros Militar de Minas Gerais - CBMMG, sendo um órgão preparado para socorrer as vítimas de AT e encaminhá-las ao atendimento médico. Em Uberlândia, no ano de 2002, o número total de vítimas de acidentes de motocicletas foi de 874 , sendo que 868 foram vítimas não fatais e 6 foi o número de vítimas fatais, conforme apresentado na tabela abaixo.

Tabela 2: Ocorrências de AT com motociclistas,CBMMG, Uberlândia, 2002.

\begin{tabular}{c|c|c|c}
\hline Ano & Total de vítimas & № de vítimas não & № de vítimas fatais \\
\hline
\end{tabular}




\section{ANAP Brasil \\ ISSN 1984-3240 \\ V. 9, n. 14}

\begin{tabular}{c|c|c|c}
\hline & motocicletas & fatais & \\
\hline 2002 & 874 & 868 & 6 \\
\hline
\end{tabular}

Fonte: BD do CBMMG (2002). Org.: LOPES, A. F. A., 2012.

Já o total de acidentes por tipo de severidade apontou que 77,93\% dos acidentados sofreram danos materiais, $17,98 \%$ sofreram ferimentos leves, 3,82\% ferimentos graves e $0,28 \%$ de mortes - sendo 35 mortes (VERTRAN, 2002), conforme o gráfico a seguir.

Gráfico1: Acidentes por tipo de severidade em Uberlândia- 2002

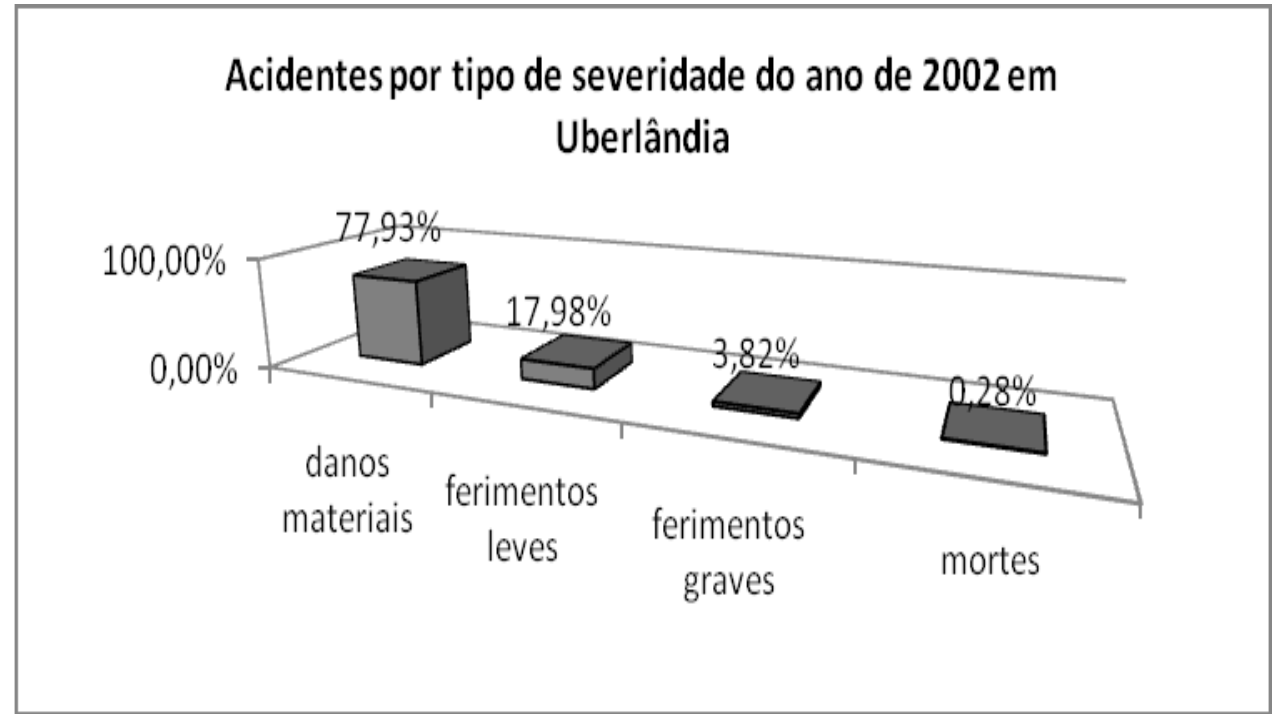

Fonte: BD de AT (VERTRAN, 2002). Org.: BRITO, L.S., 2015.

Ressalta-se que o número de mortes pode ser maior, já que as estatísticas somente levam em conta o estado da vítima no momento da ocorrência no local do acidente, sem acompanhar as condições do acidentado após socorro médico. Diante disso há a necessidade de uma integração entre os diferentes órgãos envolvidos com os acidentes de trânsito para haver uma análise da real situação que envolve o problema.

\subsection{Gênero e faixa etária dos condutores}

Em relação ao gênero, cerca de $86,13 \%$ dos motociclistas envolvidos em AT eram do sexo masculino, seguido de $13,87 \%$ do sexo feminino. 


\section{ANAP

Com relação à faixa etária, em 2002, cerca de 65,06\% dos envolvidos possuíam idade inferior a 40 anos. A faixa etária de maior envolvimento em AT foi a de 20 a 29 anos (VERTRAN, 2002). Essa realidade nos mostra que o grupo etário dos jovens se envolve mais em acidentes de trânsito, em pleno período produtivo de suas vidas.

4.5. Horário, dia da semana e mês de maior ocorrência de acidentes

A distribuição horária dos AT no ano de 2002 na cidade de Uberlândia revelou uma queda do número de ocorrências no período das 00:00 às 06:59, voltando a crescer no início da manhã (07:00 às 07:59), com pico por volta de 12:00 às 12:59, ficando praticamente homogêneo até as $16: 00$ às $16: 59$. Das $18: 00$ às 18:59 era o maior pico de ocorrência de AT, voltando a cair após as 20:59 (VERTRAN, 2002). Quanto à ocorrência por dia da semana, mostrou-se homogênea de segunda a quinta, havendo uma pequena elevação aos sábados e sextas (VERTRAN, 2002), conforme aponta o gráfico abaixo.

Gráfico 2: Ocorrência de AT motociclísticos por dia da semana - Uberlândia, 2002

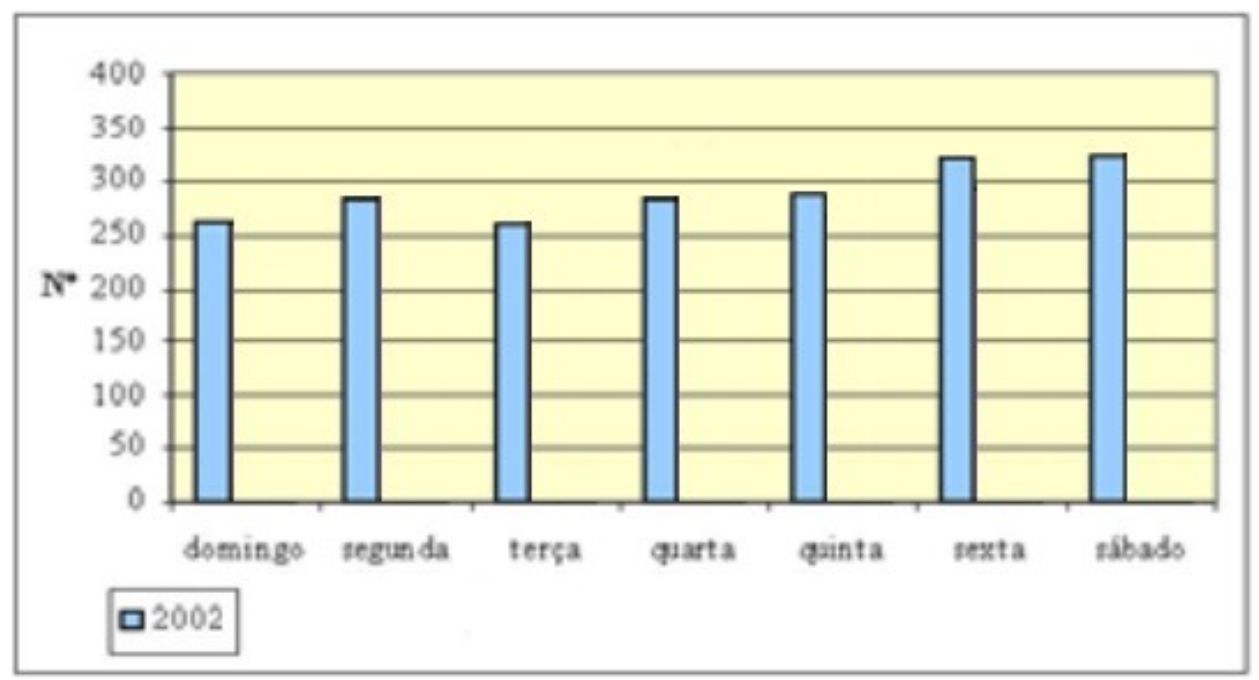

Fonte: BD de AT (VERTRAN, 2002). Adaptação: LOPES, A. F. A, 2012

Os meses de maior ocorrência de acidentes de trânsito envolvendo motociclistas em 2002 foram junho, julho, agosto, novembro e dezembro, os demais meses se manterem homogêneos, mais também com índices elevados (Gráfico 3).

Gráfico 3: Ocorrência de AT motociclísticos de acordo com o mês - Uberlândia, 2002 


\section{ANAP

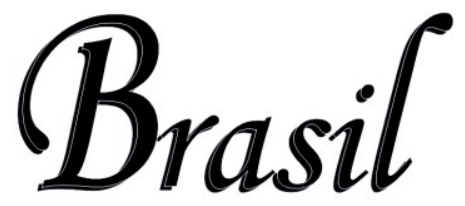 \\ ISSN $1984-3240$ \\ V. 9, n. 14}

REVISTA CIENTÍFICA

2016

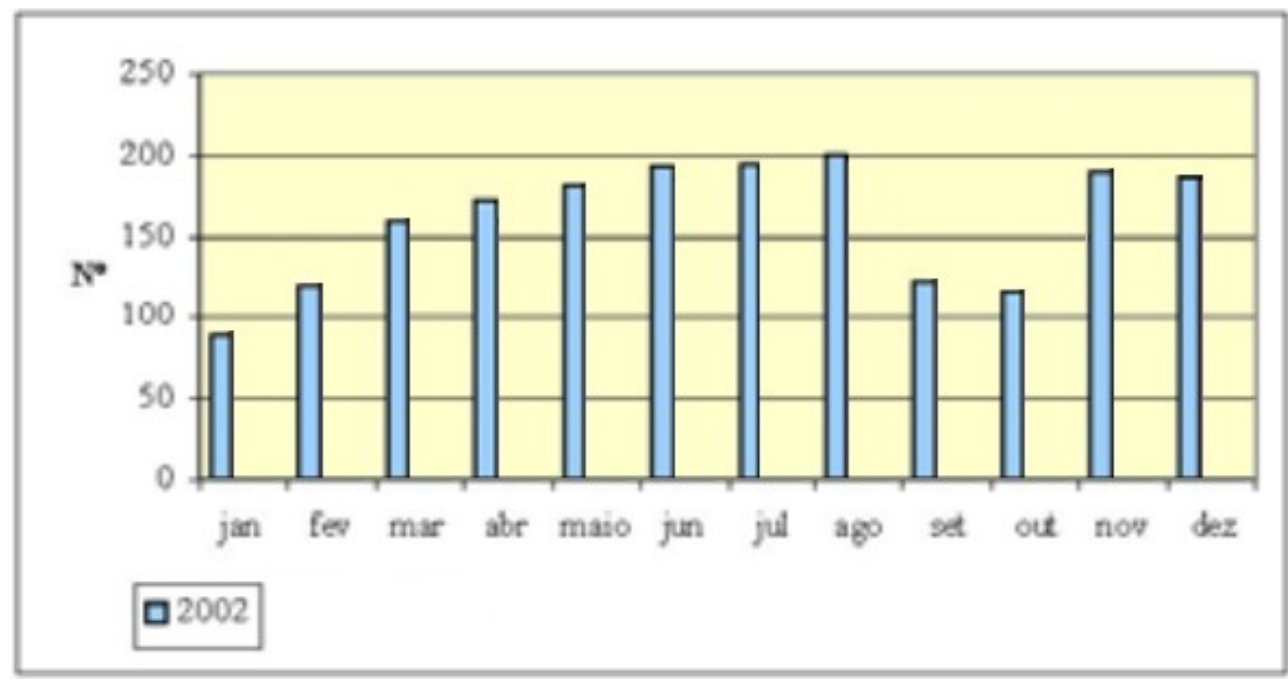

Fonte: BD de AT (VERTRAN, 2002). Org.: LOPES, A. F. A, 2012.

4.6. Internações hospitalares de motociclistas vítimas de AT e o número absoluto de vítimas fatais

Em Uberlândia, no ano de 2002, o número total óbitos equivale a 22, sendo 15 de internações e 7 de emergência, conforme a tabela abaixo.

Tabela 3: Vítimas de AT motociclístico atendidas no HCU - Uberlândia, 2002

\begin{tabular}{c|c|c|c|c}
\hline Ano & $\begin{array}{c}\text { Internação } \\
\text { №/ óbitos }\end{array}$ & $\begin{array}{c}\text { Emergência } \\
\text { №/ óbitos }\end{array}$ & $\begin{array}{c}\text { Total } \\
\text { atendimentos }\end{array}$ & $\begin{array}{c}\text { Total } \\
\text { óbitos }\end{array}$ \\
\hline 2002 & $400 / 15$ & $807 / 7$ & 1207 & 22 \\
\hline
\end{tabular}

Fonte: Setor de Nosologia do HCU (jun. 2005). Org.: LOPES, A. F. A. (2012).

O número absoluto de vítimas fatais motociclistas consta no gráfico 4 , onde é realizada a comparação com as informações de óbitos de outros órgãos. Percebe-se que as mortes provocadas por AT, além de causar prejuízos sociais e familiares, revelam apenas uma pequena parte sobre este problema, pois a quantidade de pessoas feridas e incapacitadas é, muitas vezes, superior à de mortes. 


\section{ANAP

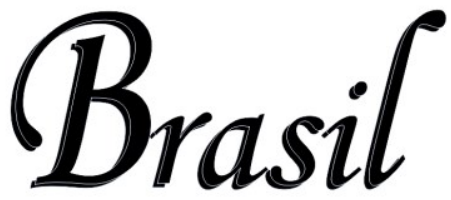

Gráfico 4: Óbito de motociclistas vítimas de acidentes de trânsito em Uberlândia: 2002

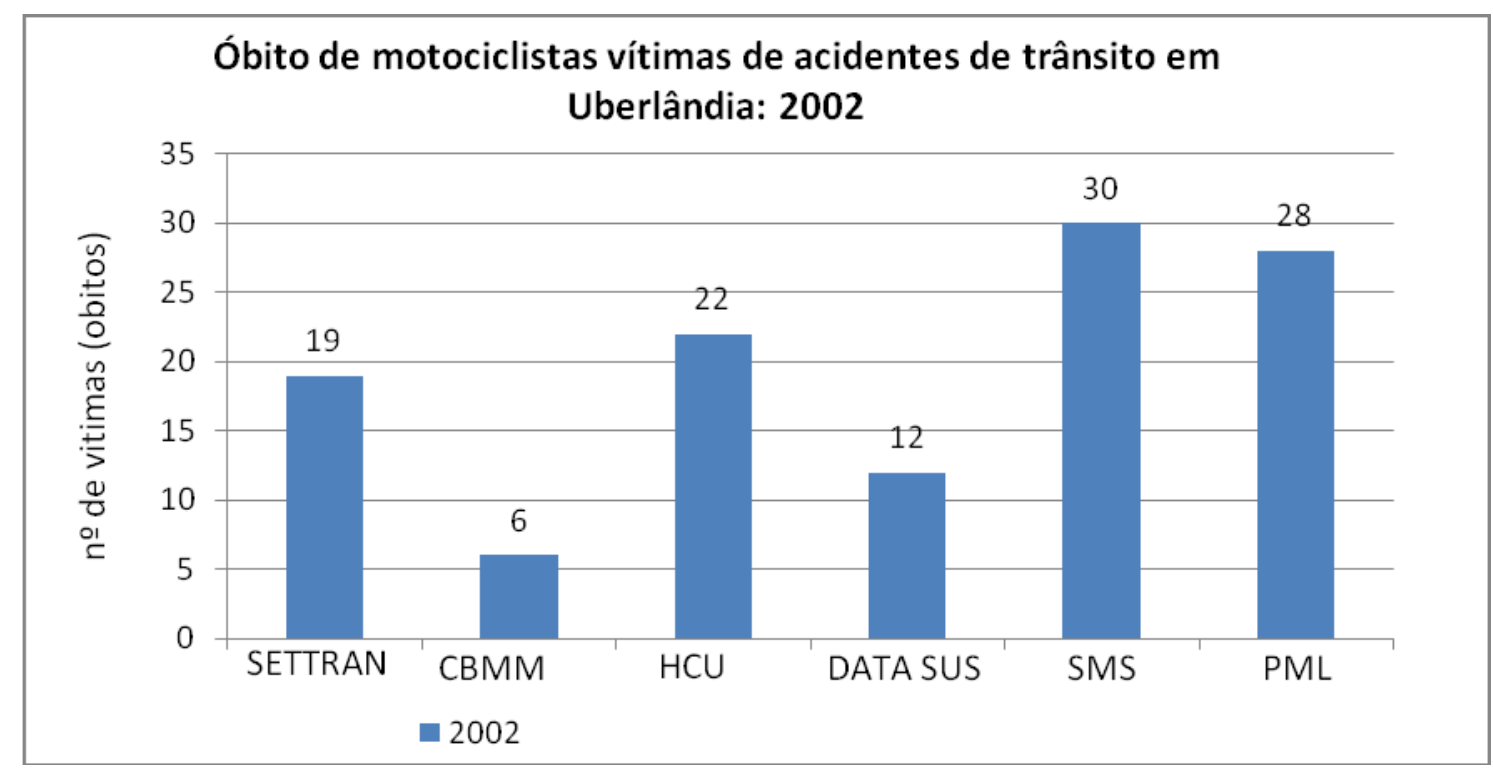

Fonte: BD de AT (VERTRAN, 2003 e 2004); BD do CBMMG (2004); PML (2005), HCU (2005), e DATASUS (BRASIL, 2006b). Org.: LOPES, A. F. A., 2002.

\section{CONCLUSÕES}

Os acidentes de trânsito, como já mencionado provocam uma insustentabilidade urbana, pois causam perda da qualidade de vida às vítimas, aos seus familiares e à sociedade como um todo, além de gastos econômicos altos, já que incluem custos com atendimento médico hospitalar, atendimento policial e de agentes de trânsito, de congestionamentos, dos danos a equipamentos urbanos, dos danos à propriedade de terceiros, dos danos à sinalização de trânsito, dos danos aos veículos, do impacto familiar, de outro meio de transporte, da perda de produção, de previdência, de processos judiciais, de remoção de veículos e resgate de vítimas, entre outros (IPEA/ANTP, 2003).

Como consequência do contínuo crescimento da frota de motocicletas na cidade de Uberlândia, ocorre na mesma um aumento significativo de acidentes envolvendo este meio automotor. As estatísticas apresentadas neste trabalho no decorrer do ano de 2002 destacam a realidade do município. Diante disto, pode-se concluir que com relação à severidade, $77,93 \%$ dos acidentados sofreram danos materiais, 17,98\% sofreram ferimentos leves, 3,82\% ferimentos graves e $0,28 \%$ de mortes. A faixa etária de maior envolvimento em AT foi a de 20 a 29 anos, ressaltando que o grupo etário dos jovens se envolve mais em acidentes de trânsito; a maior frequência dos mesmos ocorrem no final da semana e durante a semana , se mantendo homogêneos. Além destes aspectos apontados, as vítimas dos acidentes estão sujeitas a algumas consequências severas, tais como: óbitos, invalidez temporária ou permanente, anos 
de vida perdidos, prejuízos materiais e financeiros para os envolvidos e para a sociedade como um todo.

Durante o desenvolvimento da pesquisa, percebeu-se também a necessidade de integração das estatísticas de acidentes entre as instituições como banco de dados de AT da VERTRAN; banco de dados do CBMMG; da PML e do HCU. Esta integração é fundamental para conhecer a realidade sobre as vítimas envolvidas em acidentes e os óbitos, buscando reduzir as ocorrências através de políticas públicas voltadas para os meios de transporte mais vulneráveis, através da fiscalização, da educação para o trânsito e de um melhor treinamento dos condutores, dentre outros. Por fim, conclui-se que ao definir a gravidade do problema podem-se elaborar políticas públicas e agir a curto e médio prazo como forma de combater acidentes, gerar segurança, promover a saúde pública e melhorar a qualidade de vida da população. É necessário também que a administração pública da cidade de Uberlândia, caminhe rumo à meta de sustentabilidade proposta pelo Programa Cidades Sustentáveis, buscando zerar o número de mortes com os usuários de motocicleta, para que este indicador passe a ser considerado sustentável.

\section{REFERÊNCIAS}

ABRACICLO - Associação Brasileira dos Fabricantes de Motocicletas, Ciclomotores, Motonetas, Bicicletas e Similares. Distribuição Percentual Geográfica de Vendas de Motociclos. Disponível em: <http://www.abraciclo.com.br/distrib.html>. Acesso em: 20 outubro 2015.

ASSOCIAÇÃO BRASILEIRA DE NORMAS TÉCNICAS. NBR 6023: informação e documentação, referências, elaboração. Rio de Janeiro, 2002.

BRASIL. Ministério da Justiça. Departamento Nacional de Trânsito - DENATRAN. Código Nacional de Trânsito. Brasília: Senado Federal, Subsecretaria de Edições Técnicas, 1997.

Ministério da Justiça. Departamento Nacional de Trânsito - DENATRAN. Anuário Estatístico de Acidentes de Trânsito - 2002. Brasília, 2002. Disponível em: <http://www.denatran.gov.br/acidentes.htm>. Acesso em: 06 out.2015.

Ministério da Saúde. Departamento de Informática do Sistema Único de Saúde -

DATASUS. Morbidade hospitalar do SUS por causas externas por local de internação: Minas Gerais. Brasília, 2006.

CBMMG (2004) Corpo de Bombeiros Militar de Minas Gerais. Acidentes Corpo de Bombeiros. Banco de Dados. Uberlândia, 2004. 


\section{ANAP

DAVANTEL, P. P.; PELloso, S. M.; CARVALhO,M. D. de B.; OliVeirA, N. L. B. de. A mulher e o acidente de trânsito: caracterização do evento em Maringá, Paraná. Revista Brasileira Epidemiologia, 2009.

DINIZ, Magno Alves et al. Acidentes de trânsito em Minas Gerais (2003): uma abordagem espacial. Revista de Biologia e Ciências da Terra, João Pessoa, v.8, n.1, p. 1-13, 1. sem.2008.

FERREIRA, F.F. Fatores de risco em acidentes envolvendo motocicletas em vias urbanas: A percepção dos condutores profissionais. $91 \mathrm{f}$. Dissertação (Mestrado em Engenharia de Produção) - Universidade Federal do Rio Grande do Sul. Porto Alegre, 2009.

HOSPITAL de Clínicas de Uberlândia - HCU. Setor de Nosologia. Pesquisa sobre Emergências e Internações de Motociclistas. Uberlândia, 2005.

IBGE - Instituto Brasileiro de Geografia e Estatística. Cidades, 2010. Disponível em: <http://www.ibge.gov.br/cidadesat/default.php.>. Acesso em: 26 fev.2016.

IPEA; ANTP Impactos sociais e econômicos dos acidentes de trânsito nas aglomerações urbanas: relatório executivo/ IPEA, ANTP. Instituto de Pesquisa Econômica Aplicada e Associação Nacional de Transportes Públicos. Brasília, DF, 2003.

IPEA; DENATRAN; ANTP Impactos sociais e econômicos dos acidentes de trânsito nas rodovias brasileiras: Relatório Final/IPEA, DENATRAN, ANTP. Instituto de Pesquisa Econômica Aplicada, Departamento Nacional de Trânsito e Associação Nacional de Transportes Públicos. Brasília, DF, 2006.

MANICA, M. Acidentes de trânsito no Brasil: a situação nas capitais. São Paulo: ABRAMET, 2007. 256p.

ORGANIZAÇAO MUNIDIAL DA SAÚDE (OMS). Classificação estatística internacional de doenças e problemas relacionados à saúde. São Paulo: EDUSP; 2000.

Classificação estatística internacional de doenças e problemas relacionados à saúde. São Paulo: EDUSP; 2000.

ROGERS, Richard; GUMUCHDIIAN, Philip. Cidades para um pequeno planeta. Barcelona: GG, 2008. 


\section{ANAP

UBERLÂNDIA. Secretaria Municipal de Trânsito e Transportes. Controle de Tráfego em Área/CTA. Volume veicular médio por vias e volume veicular por cruzamentos. 01 out. 2006. Uberlândia, 2006.

.Secretaria Municipal de Planejamento Urbano e Meio Ambiente. Banco de Dados Integrados. Uberlândia, v. 1, 2005.

Secretaria Municipal de Saúde. Núcleo de Informação à Saúde - NIS. Óbito por acidentes de trânsito de ocorrências em Uberlândia. Uberlândia, 2006.

VERTRAN GERENCIAMENTO E CONTROLE DE TRÁFEGO. Contagem Volumétrica Direcional Classificada de Veículos na Av João Naves de Ávila. Uberlândia, ago. 2005.

Sistema de Administração de Infração de trânsito - SIAIT 2004. Banco de Dados de Acidentes de Trânsito. Uberlândia, 2004.

Sistema de Informações Gerenciais de Acidentes de Trânsito - SIGAT 2003. Banco de Dados de Acidentes de Trânsito. Uberlândia, 2003.

WHO - World Health Organization. "World report on road traffic injury prevention". Geneva: WHO. 2004.

ZAMBON E HASSELBERG. Geografia de redes y sistemas de transporte. Madrid: Sintesis, 2006. p. 9-45. 